\title{
Asian Journal of Sustainability and Social Responsibility Inaugural Editorial
}

Jong Dae Kim ${ }^{1 *}$ and Stephan Vachon ${ }^{2}$

\author{
* Correspondence: jdk@inha.ac.kr \\ ${ }^{1}$ College of Business Administration, \\ Inha University, Incheon, Korea \\ Full list of author information is \\ available at the end of the article
}

We are thrilled to welcome you to this first issue of the Asian Journal of Sustainability and Social Responsibility (AJSSR). The journal aims to provide an outlet for managerially relevant research on corporate social responsibility pertaining to sustainability challenges. Published by Springer and housed in the Sustainability Management Research Institute (SMRI) at Inha University, this open access publication provides a great channel for research dissemination on sustainability practices and performance that can be of interest for Asian businesses, government, and non-government organizations.

We are particularly proud of the AJSSR's Editorial team and review board. The Editor-in-Chief and Associate Editors are established scholars in the area of corporate sustainability, and are from leading institutions from around the world (Korea, Australia, Belgium and Canada). The Editorial Review Board of more than 25 leading sustainability scholars coming from all parts of the world will also contribute to the Journal by providing constructive reviews and suggesting manuscript's authors with improvement ideas.

\section{Why the Asian dimension for the journal?}

Having a dedicated sustainability management journal to the Asian continent can be explained by several factors. First, the weight of the continent in the global economy has grown over the last couple of decades and that growth will remain robust in the future. For example, countries located in the southeastern part of the continent are often referred to as the planet 'manufacturer'. According to the World Bank 2015 GDP data, three of the ten largest economies are in Asia (China, Japan, and India) with a combined GDP that is close to $25 \%$ of the World. Furthermore, six of the ten most populated countries (without counting Russia) are located in Asia (China, India, Indonesia, Pakistan, Bangladesh and Japan). With this size, it is not surprising that Asian countries were highly engaged in the recent international climate change negotiation and enter in an increasing number of free trade agreement including the recent Transpacific Partnership concluded with countries like the United States of America, Australia, and Canada.

The second important characteristic is the Asian continent diversity not just in terms of culture but also, and more importantly for the purpose of ASSJR, from an economic development perspective. The continent has a wide range of economic development from low income countries (e.g., Afghanistan and Nepal) to high income countries

(c) The Author(s). 2016 Open Access This article is distributed under the terms of the Creative Commons Attribution 4.0 International License (http://creativecommons.org/licenses/by/4.0/), which permits unrestricted use, distribution, and reproduction in any medium, provided you give appropriate credit to the original author(s) and the source, provide a link to the Creative Commons license, and indicate if changes were made. 
(e.g., South Korea and Japan) as per the classification provided by the World Bank. Such a diversity exemplified the tension in different aspects of sustainability similar to those experienced between the so called western industrialized countries or 'advanced' economies and most of the emerging and developing economies from Africa and South America.

Building on these two factors, AJSSR will privilege submissions pertaining to sustainability challenges and corporate social responsibility issues that are taking place in Asia. However, AJSSR remain open to studies that can be of interest and have implications for Asian organizations even if they are focusing on another area of the world. An example of a non-Asian based manuscript that may be considered for AJSSR would be a study of European companies on the management of their global supply chain (which most likely include Asian suppliers). In a nutshell, AJSSR's primary objective is for the organization outside of the Asian region to learn from Asian-based organizations and vice-versa.

\section{Publishing in AJSSR}

All manuscripts submitted are first screened for suitability to the journal. At that stage, a manuscripts may be returned to authors for a few reasons including (i) a topic outside the AJSSR's scope, (ii) a manuscript that is ill-written, or (iii) an apparent lack of sizeable contribution. Therefore, authors must assure that the topic fit with the Journal's aim and scope (as described on AJSSR's website). In doubt, the prospective authors should communicate with the Editor-in-Chief or one of the Associate Editors. Also, too many manuscripts with a good potential to make a contribution are rejected because of poor form and delivery. We urge the authors to carefully read their manuscript before submitting it and use, if necessary, a copy editor and/or a proofreader. That way, the Editorial team and reviewers can focus on the manuscript's scholar worth rather than being distracted away from it. Finally, we encourage the authors to specify the manuscript's contribution in the cover letter. It also helps the Editorial team and reviewers to have an explicit research question and the contribution stated in the manuscript's introduction.

One key element for publishing in AJSSR is managerial relevance - it is paramount. While keeping the manuscript's academic value, the implications for businesses and/or other organizations need to be clear in the manuscript. Manuscripts about public policy or non-business stakeholders with a linkage to corporate behavior, practices or performance are also welcomed.

The editorial team are strong advocates of empirical based research pertaining to corporate sustainability challenges and practices - manuscripts based on advanced mathematical development or modelling may be better served in another outlet. The research can be qualitative using case study or ethnographic approaches. It can also be quantitative, based on data from archival sources, a survey or an experiment. Experiments should be conducted with the appropriate subjects - experiments using convenient samples are not desirable.

\section{Peer reviewed open access journal}

All manuscripts are peer-reviewed by at least two reviewers to provide valuable suggestions for improving the quality of articles. The Editorial team will be diligent to keep the review process short. The feature of open access journal coupled with electronic 
distribution will make articles freely and universally accessible online, so the author's work is available to readers at no cost. Authors hold the copyrights for their work and can grant anybody the rights to reproduce and disseminate the article, provided that it is appropriately cited with no error. In particular, Sustainability Management Research Institute, the Society for the AJSSR, proudly supports the article processing fee to enhance the accessibility of the journal for the authors.

We are looking forward to reading your research and hope we can count on you in the review process - your contribution in both is key for the journal's success.

Author details

${ }^{1}$ College of Business Administration, Inha University, Incheon, Korea. ${ }^{2}$ Ivey Business School, Western University, London, Canada.

Received: 31 October 2016 Accepted: 31 October 2016

Published: 12 December 2016

Submit your manuscript to a SpringerOpen ${ }^{\circ}$ journal and benefit from:

- Convenient online submission

- Rigorous peer review

- Immediate publication on acceptance

- Open access: articles freely available online

- High visibility within the field

- Retaining the copyright to your article

Submit your next manuscript at $>$ springeropen.com 